\title{
SCIDOC
}

\author{
International Journal of Dentistry and Oral Science (IJDOS) \\ ISSN: 2377-8075
}

\section{Dentists's Preference Of Brushing Technique Taught To Children With Permanent Dentition}

Research Article

R.Kushali ${ }^{1}$, Vignesh Ravindran ${ }^{2 *}$

${ }^{1}$ Saveetha Dental College and Hospitals, Saveetha Institute of Medical and Technical Sciences (SIMATS), Saveetha University, Chennai- 77, India. ${ }^{2}$ Senior Lecturer, Department of Pediatric and Preventive Dentistry, Saveetha Dental College and Hospitals, Saveetha Institute of Medical and Technical Sciences [SIMATS], Saveetha University, Chennai- 77, India.

\section{Abstract}

Introduction: Oral health is believed to be commonly correlated with systemic health. Brushing daily is a sufficient method to avoid interdental caries and gingivitis. There are a number of techniques that are used for tooth brushing for plaque removal. Various techniques include fones technique, Horizontal scrub. Modified bass, Charter's method, Stillman's method, roll's method.

Aim: The aim of the study was to know the dentist's preference of brushing technique taught to children with permanent dentition.

Materials and Method: A retrospective study was conducted among patients visiting dental hospitals with the help of dental records from Saveetha dental college and hospitals and various other clinics. The required data was collected and made into excel sheets and statistically analysed using SPSS software. Chi square test was done to compare the results based on gender and age.

Results: The maximum number of patients were $25.42 \%$ who were 17 years old. The study showed $49.6 \%$ of male and $50.3 \%$ were females. The study shows that $52.83 \%$ of the patients were taught modified bass technique and is the most preferred brushing technique amongst the other brushing techniques. No significant difference was obtained when comparisons were made based on gender and age of the patient ( $\mathrm{p}$-value $0.26 \& 0.19$ respectively).

Conclusion: Modified bass technique is the most preferred brushing technique by dentists for children with permanent dentition.

Keywords: Brushing Techniques; Permanent Dentition; Dental Caries; Dental Plaque; Innovative Material.

\section{Introduction}

Oral health is believed to be commonly correlated with systemic health. Tooth brushing is an important part of dental care hygiene which includes an act of scrubbing the teeth using a toothbrush and a toothpaste [1]. It is an efficient method to maintain good oral hygiene and importantly prevent dental caries. Dental caries, otherwise known as tooth decay, is one of the most prevalent chronic diseases of people worldwide; individuals are susceptible to this disease throughout their lifetime [2]. Dental caries form through a complex interaction over time between acid-producing bacteria and fermentable carbohydrate, and many host factors including teeth and saliva [3]. It affects both the crowns and roots of teeth, and it can arise in early childhood as an aggressive tooth decay that affects the primary teeth of infants and toddlers [4]. Risk for caries includes physical, biological, environmental, behavioural, and lifestyle-related factors such as high numbers of cariogenic bacteria, inadequate salivary flow, insufficient fluoride exposure, poor oral hygiene, inappropriate methods of feeding infants, and poverty [5]. The approach to primary prevention should be based on common risk factors. Secondary prevention and treatment should focus on management of the caries process over time for individual patients, with a minimally invasive, tissuepreserving approach [6].

Dental caries is the most common problem in children between the age group of 10-16, worldwide [7]. It can cause restlessness,

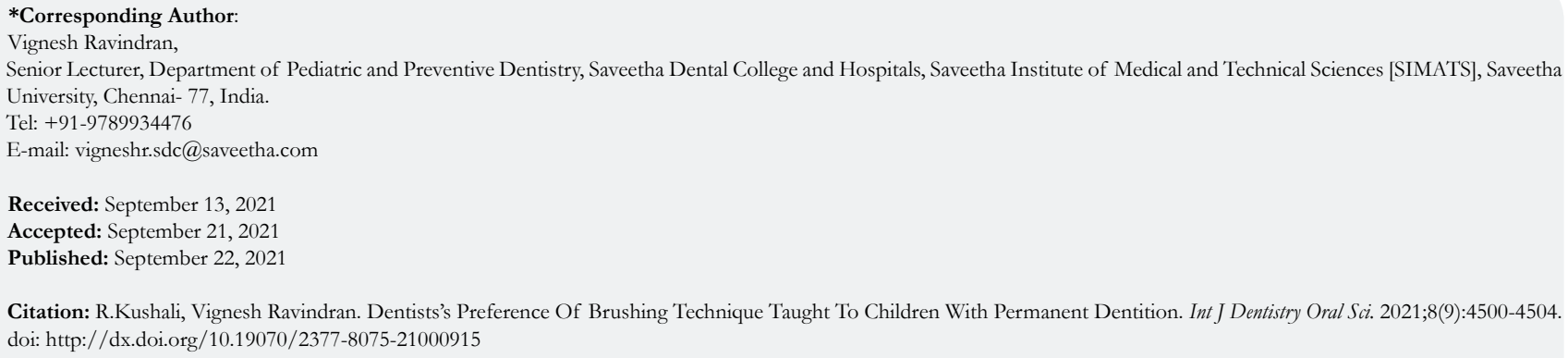

Copyright: Vignesh Ravindran 2021 . This is an open-access article distributed under the terms of the Creative Commons Attribution License, which permits unrestricted use, distribution and reproduction in any medium, provided the original author and source are credited. 
pain, poor eating habits and all together leading to esthetic problems. It also helps in preventing further periodontal problems. Accumulation of microbial plaque which adheres to the tooth structure can be prevented [8]. Brushing daily is a sufficient method to avoid interdental caries and gingivitis. Biofilms are a complex group of bacteria which are found on the tooth structure [9]. If these biofilms are not removed regularly, subgingival plaque can cause periodontitis. Tooth brushing is one of the most effective mechanical methods for plaque removal. Studies have shown that manual toothbrushes are an effective tool in preventing gingivitis and removing bacterial plaque [10]. Tooth brushes are over the counter products, hence no special instructions for use is given. The normal tooth brushing practice if adequately performed is sufficient to control dental plaque. Tooth brushing reduces dental plaque and improves oral hygiene.

Dentists can improve the oral hygiene of the patient using tooth brushing by two means $[11,12]$. Either advocating use of specific tooth brushing method or by improving the performance of normal tooth brushing method but most of the studies have shown specific tooth brushing technique have better result as compared to normal tooth brushing practices [13]. There are a number of techniques that are used for tooth brushing for plaque removal. Various techniques include fones technique, Horizontal scrub. Modified bass, Charter's method, Stillman's method, roll's method. Fones's technique is also called the circular technique. It includes a toothbrush held at right angle to the tooth surface and large sweeping motion and scrubbing circles are made over the occluded teeth in this technique [14]. In horizontal scrub, brush is held at a $45^{\circ}$ angle to the neck of the tooth and is moved across the surface of the tooth in short horizontal movements [15]. In modified bass, brush is placed directed apically $45^{\circ}$ angle to the tooth surface. The bristle is pressed slightly so that they enter the gum line, vibrate the brush back and forth with 10-15 strokes for each position and then roll the brush towards the occlusal surface of the teeth, full tufts occlusally after cleaning the cervical area [16]. In charter's technique the bristles are held at an angle of $45^{\circ}$ to the gym driver with the bristles directed coronally [17]. The bristles are activated by mild vibratory stocks. In roll's technique the toothbrush is rolled across the tooth surface towards the occlusal surface. This technique requires some flexibility around the rest by holding the bristles at 45 angles [18]. Our team has extensive knowledge and research experience that has translate into high quality publications [19-31, 32-38].

The main aim of the study was to know the dentist's preference of brushing techniques taught to children with permanent dentition.

\section{Materials and Methods}

The study was done under a university setting. The Ethical approval was obtained from the Institutional ethical committee. About 2,00,000 case sheets were obtained from June 2019 to March 2021. Informed consent was obtained from the parents or guardian regarding usage of the clinical data for research purposes.

Inclusion criteria were patients between the age group of 13-17 years and patients who were taught different brushing techniques as an oral hygiene instruction. Exclusion criteria includes patients below 13 years of age and above 18 years of age, and those patients who were not taught different brushing techniques as an oral hygiene instruction.

Digital entry of clinical examination, intraoral photographs of the oral cavity and the treatment procedure were assessed. The data collected (digital entry and intraoral photographs) was verified by an external additional reviewer. The sampling bias was minimised by a simple random sampling method. If any error in data entry or patient details or clinical data were noticed, that case sheet was excluded from the study.

The data collected were tabulated in MS Excel and was then analysed in SPSS software version 22 (IBM Corp, Texas, LA). Descriptive statistics were used and comparison between groups were done by using Chi square tests.

\section{Results}

In the current study, the percentage of male and female patients who were taught various brushing techniques is almost equal with $49.63 \%$ of females and $50.37 \%$ of males (figure 1 ). Majority of participants were 17 years of age $(25.48 \%$ )(Figure 2$) .10 \%$ were taught fones technique, 51\% were taught modified bass technique, $35.12 \%$ were taught bass technique, $1.48 \%$ were taught charter's method, $1.54 \%$ were taught Stillman's method, $0.68 \%$ were taught roll's method (figure 3). Association between gender and the different brushing techniques showed $26.2 \%$ and $24.8 \%$ of male and females shows respectively were taught modified bass technique which was not statistically significant ( $\mathrm{p}$-value $=$ 0.26)(Figure 4). Association between age and different brushing techniques showed modified bass technique was mostly taught to children of all age groups, which was not statistically significant $(\mathrm{p}$-value $=0.19)($ Figure 5$)$.

Figure 1. The bar graph above represents the gender of the population. The $\mathbf{X}$-axis represents gender and $\mathbf{y}$-axis represents number of patients. The yellow denotes male and grey denotes females which includes $49.08 \%$ of males and $50.92 \%$ of females.

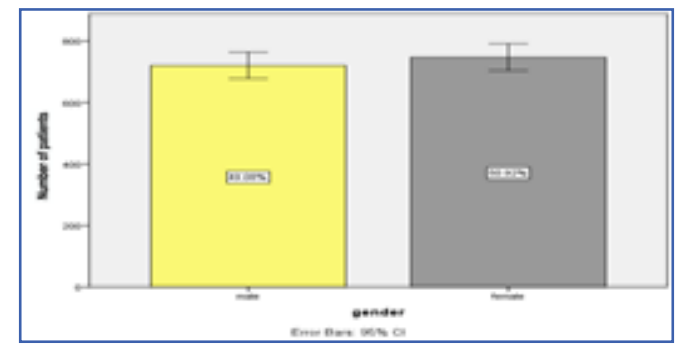


Figure 2. The above bar graph represents the age group of children. The $\mathrm{X}$-axis represents age and $\mathrm{Y}$-axis represents number of patients. The black colour denotes 13 years, green colour denotes 14 years, orange colour denotes 15 years, red colour denotes 16 years and blue denotes 17 years of age. $21.8 \%, 15.88 \%, 16.7 \%, 20.86 \%, 25.74 \%$ were the percentage of age groups involved in the study from 13 to 17 years respectively.

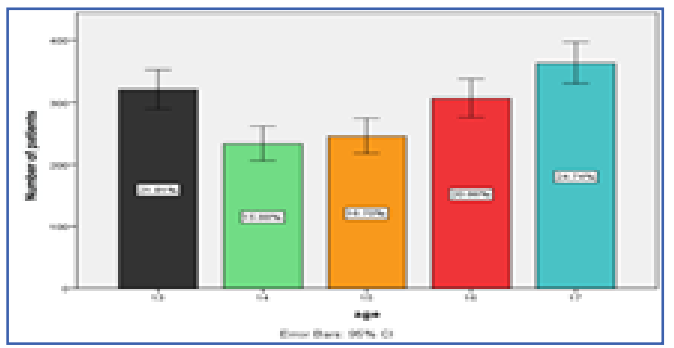

Figure 3. The figure 3 represents the different brushing techniques used by dentists which were preferably used to teach children with permanent dentition. The $\mathrm{X}$-axis represents brushing technique and $\mathrm{Y}$-axis represents percentage of patients.

Green denotes fone's technique, yellow denotes modified bass technique, violet denotes bass technique, light yellow denotes charter's method, and red denotes stillman's method and light blue denotes roll's method. $10 \%$ used fones technique, $51 \%$ used modified bass technique, $35.12 \%$ used bass technique, $1.48 \%$ charter's method, $1.54 \%$ Stillman's method, $0.68 \%$ roll's method.

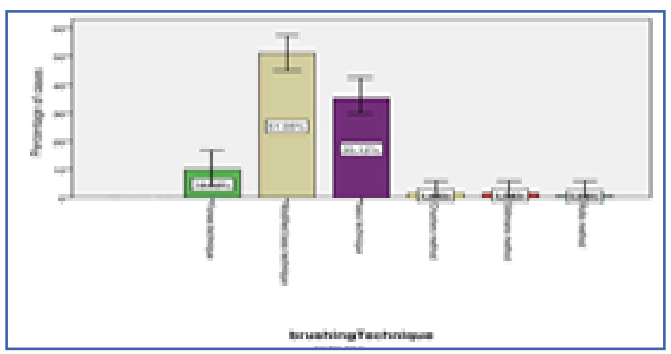

Figure 4. The above chart represents an association between gender and the different brushing techniques. The $\mathrm{X}$-axis represents gender and $\mathrm{Y}$-axis represents percentage of patients. 5.1\% and $4.9 \%$ of male and females respectively were taught fone's technique, $26.2 \%$ and $24.8 \%$ of male and females respectively were taught modified bass technique, $16.42 \%$ and $18.7 \%$ of male and females respectively were taught bass technique, $0.68 \%$ and $0.8 \%$ of male and females respectively were taught charter's technique, $0.37 \%$ and $0.31 \%$ of male and females respectively were taught roll's technique. (Pearson's

Chi-square test - p-value $=0.26$ - not significant).

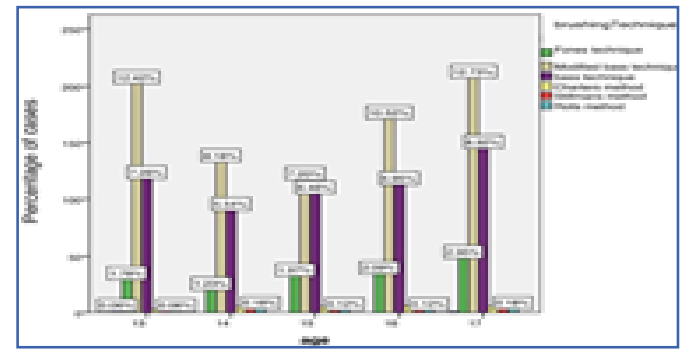

Figure 5. The bar graph represents an association between age and different brushing techniques. The $\mathrm{X}$-axis represents age and $\mathrm{Y}$-axis represents percentage of patients.12.42\%, 8.18\%, 7.2\%, 10.52\% and 12.73\% were taught modified bass technique from the 13 to 17 years respectively. (Pearson's Chi-square test - p-value $=0.19$ - not significant).

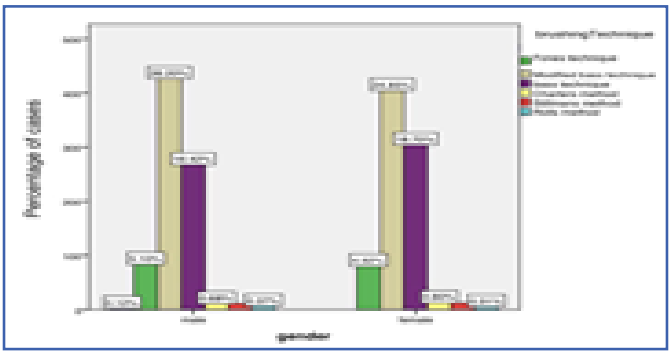

\section{Discussion}

The modified bass technique is the most preferred brushing technique taught to children with permanent dentition with a percentage of $51.05 \%$ when compared to other techniques. $26.20 \%$ of males were taught modified bass technique over the other tech- niques. The patients who were 17 years old were maximum who also were taught modified bass technique with a $12.73 \%$. Previous studies show reduction in plaque score in modified bass technique, followed by horizontal technique. The fones technique showed least efficacy [15]. A study by Hrnacke et al., shows that plaque levels reduced in patients who were trained with Fone's technique after a span of 12 weeks [39]. Earlier studies, modi- 
fied Bass technique was also reported to be superior in reducing supragingival plaque than Normal tooth brushing practices. An optimal reduction in plaque with adequate protection of the oral tissues against mechanical trauma is achieved by manual tooth brushing with the use of Modified Bass technique [40].

From the data obtained, it is observed that Modified bass technique is the commonly taught technique for the children of 1317 years of age. Modified bass technique is considered to be the most effective brushing techniques according to previous studies. It has a better effect of plaque removal compared to the vertical method [41]. It is highly recommended for easy plaque control and it causes good gingival stimulation. Modified bass technique is suitable for short term effects but it couldn't sustain long term effects [42]. Possible reasons for the high frequency of recommending the Modified Bass technique is that there's some, but not excellent evidence, suggesting that the technique is better than other techniques in terms of improved plaque control and reducing gingival inflammation. However, there are some studies to add evidence to such findings. The evidence that does exist usually involves a little number of participants, with a brief follow-up, and ranging levels of bias. Moreover, few studies suggest that other brushing techniques are easier and simpler than the Modified Bass technique [43].

Based on the gender of the patients, Modified bass technique is preferred more among males than females. The possible reasons could be increased manual dexterity in males compared to females. According to the age of the patients, Modified bass technique is recommended for age group 16-17 years mostly. Dexterity of the wrist is required hence it is preferred in late childhood. Complex brushing techniques like Modified bass are technically more demanding compared to simpler techniques like Scrub or Fones. Therefore children will find the Modified bass technique more difficult to master [44]. There were large differences between the techniques recommended for adults and for youngsters. The Bass and Modified Bass methods were most often advocated for adults but not for youngsters. On the opposite hand, the Scrub and Fones techniques were more frequently recommended for youngsters [45]. Modified Bass Technique has been proven to get rid of enough of the plaque compared to normal tooth brushing technique on lingual and buccal sites. Dentists agree that using Modified Bass Technique over traditional tooth brushing is best in removing supragingival plaque [46]. When patients start to use a far better cleaning option like modified bass technique, their oral hygiene will improve generally [47]. There also are many studies that are done to match Modified Bass Technique with other available tooth cleaning methods and most of the time Modified Bass technique was proven to be superior to others $[46,48]$.

This study is limited by a few factors such as small sample size. It also has geographical limitations since it is a hospital setting. It is a unicentric study with no external validity. The sample size and duration of the study can be expanded. A multicentric study can be done on Effective brushing technique for plaque control, caries and periodontal problems prevention. A large sample size of people from different ethnicities would give better results for the study. Additional repeated population-based investigations covering extended time periods would help add important information in these areas and further validate the findings. Future research is required to raise understanding which factors impede adoption of tooth brushing recommendations in children and which efforts are necessary to enhance their tooth brushing abilities.

\section{Conclusion}

From the study it can be concluded that the modified bass method of brushing is the most preferred brushing technique by dentists, followed by the bass technique of brushing. There were no differences in the technique taught to children based on gender or age.

\section{Acknowledgement}

The authors are thankful to the Department of Pediatric Dentistry, Saveetha dental college, Saveetha Institute of Medical and Technical Science, Saveetha University for providing a platform in expressing their knowledge.

\section{Source of Funding}

The present project was funded by

- Saveetha Dental College

- Saveetha Institute of Medical and Technical Sciences

- Saveetha University

- Rajendra kumar auto finance private ltd.

\section{References}

[1]. Ilyas M, Ashraf S, Jamil H. Tooth brushing techniques. Prof. med. j. 2018 Jan 10;25(01):135-9.

[2]. Selwitz RH, Ismail AI, Pitts NB. Dental caries. The Lancet. 2007 Jan 6;369(9555):51-9.

[3]. Holmes RD. Tooth brushing frequency and risk of new carious lesions. Evid Based Dent. 2016 Dec;17(4):98-9.

[4]. Aoba T. Solubility properties of human tooth mineral and pathogenesis of dental caries. Oral Dis. 2004 Sep;10(5):249-57.

[5]. Reisine ST, Psoter W. Socioeconomic status and selected behavioral determinants as risk factors for dental caries. J Dent Educ. 2001 Oct;65(10):100916.

[6]. Tinanoff N. Dental caries risk assessment and prevention. Dent Clin North Am. 1995 Oct 1;39(4):709-19.

[7]. Mahejabeen R, Sudha P, Kulkarni SS, Anegundi R. Dental caries prevalence among preschool children of Hubli: Dharwad city. J Indian Soc Pedod Prev Dent. 2006 Mar;24(1):19-22.Pubmed PMID: 16582526.

[8]. Marsh PD, Bradshaw DJ. Dental plaque as a biofilm. J. Ind. Microbiol. Biotechnol. 1995 Sep 1;15(3):169-75.

[9]. Marsh PD. Microbial ecology of dental plaque and its significance in health and disease. Adv Dent Res. 1994 Jul;8(2):263-71.

[10]. Creeth J, Zero D, Mau M, Bosma ML, Butler A. The effect of dentifrice quantity and toothbrushing behaviour on oral delivery and retention of fluoride in vivo. Int Dent J. 2013 Dec;63 Suppl 2:14-24.Pubmed PMID: 24283280.

[11]. Sharma S, Yeluri R, Jain AA, Munshi AK. Effect of toothbrush grip on plaque removal during manual toothbrushing in children. J Oral Sci. 2012;54(2):183-90.

[12]. van der Weijden GA, Hioe KP. A systematic review of the effectiveness of self-performed mechanical plaque removal in adults with gingivitis using a manual toothbrush. J Clin Periodontol. 2005;32 Suppl 6:214-28.Pubmed PMID: 16128840.

[13]. Giri DK. Effectiveness between two tooth brushing methods on removing dental plaque. J. Nobel Med. Coll. 2018 Aug 22;7(1):26-9.

[14]. Harnacke D, Mitter S, Lehner M, Munzert J, Deinzer R. Improving oral hygiene skills by computer-based training: a randomized controlled comparison of the modified Bass and the Fones techniques. PLoS One. 2012;7(5):e37072.Pubmed PMID: 22629353.

[15]. Patil SP, Patil PB, Kashetty MV. Effectiveness of different tooth brushing techniques on the removal of dental plaque in 6-8 year old children of Gulbarga. J Int Soc Prev Community Dent. 2014 May;4(2):113-6.Pubmed PMID: 25254196.

[16]. Poyato-Ferrera M, Segura-Egea JJ, Bullón-Fernández P. Comparison of modified Bass technique with normal toothbrushing practices for efficacy in 
supragingival plaque removal. Int J Dent Hyg. 2003 May;1(2):110-4.Pubmed PMID: 16451532.

[17]. Hansen F, Gjermo P. The plaque-removing effect of four toothbrushing methods. Eur. J. Oral Sci. 1971 Aug;79(4):502-6.

[18]. Gibson JA, Wade AB. Plaque removal by the Bass and Roll brushing techniques. J Periodontol. 1977 Aug 1;48(8):456-9.

[19]. Subramanyam D, Gurunathan D, Gaayathri R, Vishnu Priya V. Comparative evaluation of salivary malondialdehyde levels as a marker of lipid peroxidation in early childhood caries. Eur J Dent. 2018 Jan-Mar;12(1):67-70. Pubmed PMID: 29657527.

[20]. Ramadurai N, Gurunathan D, Samuel AV, Subramanian E, Rodrigues SJ. Effectiveness of $2 \%$ Articaine as an anesthetic agent in children: randomized controlled trial. Clin. Oral Investig. 2019 Sep;23(9):3543-50.

[21]. Ramakrishnan M, Dhanalakshmi R, Subramanian EMG. Survival rate of different fixed posterior space maintainers used in Paediatric Dentistry - A systematic review. Saudi Dent J. 2019 Apr;31(2):165-172.Pubmed PMID: 30983825 .

[22]. Jeevanandan G, Thomas E. Volumetric analysis of hand, reciprocating and rotary instrumentation techniques in primary molars using spiral computed tomography: An in vitro comparative study. Eur J Dent. 2018 JanMar;12(1):21-26.Pubmed PMID: 29657521.

[23]. Princeton B, Santhakumar P, Prathap L. Awareness on Preventive Measures taken by Health Care Professionals Attending COVID-19 Patients among Dental Students. Eur J Dent. 2020 Dec;14(S 01):S105-S109.Pubmed PMID: 33321549.

[24]. Saravanakumar K, Park S, Mariadoss AVA, Sathiyaseelan A, Veeraraghavan VP, Kim S, et al. Chemical composition, antioxidant, and anti-diabetic activities of ethyl acetate fraction of Stachys riederi var. japonica (Miq.) in streptozotocin-induced type 2 diabetic mice. Food Chem Toxicol. 2021 Sep;155:112374.Pubmed PMID: 34186120

[25]. Wei W, Li R, Liu Q, Seshadri VD, Veeraraghavan VP, Mohan SK, et al. Amelioration of oxidative stress, inflammation and tumor promotion by Tin oxide-Sodium alginate-Polyethylene glycol-Allyl isothiocyanate nanocomposites on the 1,2-Dimethylhydrazine induced colon carcinogenesis in rats. Arab. J. Chem. 2021 Jun 3;14(8):103238.

[26]. Gothandam K, Ganesan VS, Ayyasamy T, Ramalingam S. Antioxidant potential of theaflavin ameliorates the activities of key enzymes of glucose metabolism in high fat diet and streptozotocin - induced diabetic rats. Redox Rep. 2019 Dec;24(1):41-50.Pubmed PMID: 31142215.

[27]. Su P, Veeraraghavan VP, Krishna Mohan S, Lu W. A ginger derivative, zingerone-a phenolic compound-induces ROS-mediated apoptosis in colon cancer cells (HCT-116). J Biochem Mol Toxicol. 2019 Dec;33(12):e22403. Pubmed PMID: 31714660.

[28]. Mathew MG, Samuel SR, Soni AJ, Roopa KB. Evaluation of adhesion of Streptococcus mutans, plaque accumulation on zirconia and stainless steel crowns, and surrounding gingival inflammation in primary molars: randomized controlled trial. Clin Oral Investig. 2020 Sep;24(9):3275-3280.Pubmed PMID: 31955271

[29]. Sekar D, Johnson J, Biruntha M, Lakhmanan G, Gurunathan D, Ross K. Biological and clinical relevance of microRNAs in mitochondrial diseases/ dysfunctions. DNA Cell Biol. 2020 Aug 1;39(8):1379-84.

[30]. Velusamy R, Sakthinathan G, Vignesh R, Kumarasamy A, Sathishkumar D, Priya KN, et al. Tribological and thermal characterization of electron beam physical vapor deposited single layer thin film for TBC application. Surf Topogr: Metrol Prop. 2021 Jun 24;9(2):025043.

[31]. Aldhuwayhi S, Mallineni SK, Sakhamuri S, Thakare AA, Mallineni S, Sajja R, et al. Covid-19 Knowledge and Perceptions Among Dental Specialists: A Cross-Sectional Online Questionnaire Survey. Risk Manag Healthc Policy. 2021 Jul 7;14:2851-2861.Pubmed PMID: 34262372.

[32]. Sekar D, Nallaswamy D, Lakshmanan G. Decoding the functional role of long noncoding RNAs (lncRNAs) in hypertension progression. Hypertens Res. 2020 Jul;43(7):724-725.Pubmed PMID: 32235913.

[33]. Bai L, Li J, Panagal M, M B, Sekar D. Methylation dependent microRNA $1285-5$ p and sterol carrier proteins 2 in type 2 diabetes mellitus. Artif Cells Nanomed Biotechnol. 2019 Dec;47(1):3417-3422.Pubmed PMID: 31407919.

[34]. Sekar D. Circular RNA: a new biomarker for different types of hypertension. Hypertens Res. 2019 Nov;42(11):1824-5.

[35]. Sekar D, Mani P, Biruntha M, Sivagurunathan P, Karthigeyan M. Dissecting the functional role of microRNA 21 in osteosarcoma. Cancer Gene Ther. 2019 Jul;26(7-8):179-182.Pubmed PMID: 30905966.

[36]. Duraisamy R, Krishnan CS, Ramasubramanian H, Sampathkumar J, Mariappan S, Navarasampatti Sivaprakasam A. Compatibility of Nonoriginal Abutments With Implants: Evaluation of Microgap at the Implant-Abutment Interface, With Original and Nonoriginal Abutments. Implant Dent. 2019 Jun;28(3):289-295.Pubmed PMID: 31124826.

[37]. Parimelazhagan R, Umapathy D, Sivakamasundari IR, Sethupathy S, Ali D, Kunka Mohanram R, et al. Association between Tumor Prognosis Marker Visfatin and Proinflammatory Cytokines in Hypertensive Patients. Biomed Res Int. 2021 Mar 16;2021:8568926.Pubmed PMID: 33816632.

[38]. Syed MH, Gnanakkan A, Pitchiah S. Exploration of acute toxicity, analgesic, anti-inflammatory, and anti-pyretic activities of the black tunicate, Phallusia nigra (Savigny, 1816) using mice model. Environ Sci Pollut Res Int. 2021 Feb;28(5):5809-5821.Pubmed PMID: 32978735.

[39]. Harnacke D, Stein K, Stein P, Margraf-Stiksrud J, Deinzer R. Training in different brushing techniques in relation to efficacy of oral hygiene in young adults: a randomized controlled trial. J Clin Periodontol. 2016 Jan;43(1):4652.Pubmed PMID: 26660396.

[40]. Janakiram C, Varghese N, Venkitachalam R, Joseph J, Vineetha K. Comparison of modified Bass, Fones and normal tooth brushing technique for the efficacy of plaque control in young adults- A randomized clinical trial. J Clin Exp Dent. 2020 Feb 1;12(2):e123-e129.Pubmed PMID: 32071693.

[41]. Joybell C, Krishnan R, V SK. Comparison of Two Brushing MethodsFone's vs Modified Bass Method in Visually Impaired Children Using the Audio Tactile Performance (ATP) Technique. J Clin Diagn Res. 2015 Mar;9(3):ZC19-22.Pubmed PMID: 25954698

[42]. Alnakhli A, Omar OM. Effectiveness of two instruction methods in improving tooth brushing skills in children: A clinical trial. J Adv Med Med Res. 2016 Aug 18:1-5.

[43]. Ceyhan D, Akdik C, Kirzioglu Z. An educational programme designed for the evaluation of effectiveness of two tooth brushing techniques in preschool children. Eur J Paediatr Dent. 2018 Sep 1;19(3):181-6.

[44]. Rojlakkanawong N, Mahidon M, Mahāwitthayālai Mahidon. Faculty of Dentistry. A 6-month Comparison of Toothbrushing Efficacy Between Horizontal Scrub and Modified Bass Methods in Visually Impaired Students. 2010:122.

[45]. Gluch JI. As an adjunct to tooth brushing, interdental brushes (IDBs) are more effective in removing plaque as compared with brushing alone or the combination use of tooth brushing and dental floss. Journal of Evidence Based Dental Practice. 2012 Jun 1;12(2):81-3.

[46]. Padbury AD. A Comparative Study of Abrasion Caused by Three Methods of Toothbrushing: A Thesis Submitted in Partial Fulfillment. Periodontics. UMICH; 1968:124.

[47]. Govindaraju L, Gurunathan D. Effectiveness of Chewable Tooth Brush in Children-A Prospective Clinical Study. J Clin Diagn Res. 2017 Mar;11(3):ZC31-ZC34.Pubmed PMID: 28511505.

[48]. Shick RA. A Clinical Evaluation of the Vertical Technic of Toothbrushing with an Adjustable Head Toothbrush: A Thesis Submitted in Partial Fulfillment... Periodontics... UMICH; 1960:80. 